\title{
Mechanism of Tetracycline Resistance in Staphylococcus aureus
}

\author{
By D. SOMPOLINSKY, Y. ZAIDENZAIG, RUTH ZIEGLER- \\ SCHLOMOWITZ AND NILI ABRAMOVA \\ Rapaport Laboratories for Microbiology, Bar Ilan University, Ramat Gan, and \\ Department of Bacteriology, Asaf Harofe Government Hospital. \\ University of Tel-Aviv Medical School, Zrifin, Israel
}

(Accepted for publication I5 May 1970)

\begin{abstract}
SUMMARY
Resistance of Staphylococcus aureus I I to tetracycline was due to an extrachromosomal genetic unit (plasmid) that could be eliminated by growth at $44^{\circ}$. The susceptible (eliminated) strain actively concentrated tetracycline from the nutrient medium by an energy-dependent transport system. The resistant culture accumulated the drug to a much lesser degree than the susceptible culture, both according to the $E 380$ of the bacterial extract and to its radioactivity after incubation with tritiated tetracycline. Accumulation of tetracycline was low and independent of the external concentration until this reached a level corresponding approximately to the minimal inhibitory concentration.

Pre-incubation with tetracycline at low concentrations decreased ability to accumulate the drug. This pre-incubation effect was not prevented by nalidixic acid but was by actinomycin $\mathrm{D}$.
\end{abstract}

\section{INTRODUCTION}

In a previous communication we reported that subinhibitory amounts of tetracycline cause a temporary lag in the growth of an exponentially growing culture of Staphylococcus aureus II I, but thereafter growth continues at the original rate. The duration of growth inhibition depends on the drug concentration. This pattern of inhibition can be due to (i) inactivation of a bacteriostatic drug (Sompolinsky \& Samra, I968), (ii) selection of resistant bacteria from a heterogeneous population, (iii) development of a higher level of resistance by induction. Both selection of resistant cocci and induction contributed to tetracycline resistance (Sompolinsky, Krawitz, Zaidenzaig \& Abramova, I970). The present study deals with the mechanism of tetracycline resistance of $S$. aureus I I I. Two possible mechanisms were investigated, inactivation of the drug and decreased uptake by the resistant cells.

\section{METHODS}

Bacterial strains. The strain used, Staphylococcus aureus I I I, has been described by Sompolinsky et al. (1970). For bioassay of tetracycline (Tc) we used the same strain of Shigella boydii as was used for assay of chloramphenicol (Sompolinsky \& Samra, 1968).

Chemicals. The reagents used, with the exception of those described below, were the same as in the previous paper (Sompolinsky et al. 1970). The following were also 
used: $\left[{ }^{14} \mathrm{C}\right] \mathrm{D}$-threo-chloramphenicol (methylene- ${ }^{14} \mathrm{C}$ ) of specific activity $6 \cdot 8 \mathrm{I} \mathrm{mCi}$ / mmole, obtained from the Radiochemical Centre, Amersham, Buckinghamshire, England, and $\left[{ }^{3} \mathrm{H}\right]$ tetracycline- $7-{ }^{3} \mathrm{H}(\mathrm{N}) \mathrm{HCl}$ (specific activity $\mathrm{I} / 4 \mathrm{mCi} / \mathrm{mmole}$ ) from New England Nuclear Corporation, Boston, Mass., U.S.A. Chemicals for chromatography (see below) were of the highest purity obtainable commercially.

Bioassay of tetracycline was performed, essentially in the same way as for chloramphenicol (Sompolinsky \& Samra, 1968), on samples of nutrient broth (NB)+ I $60 \mu \mathrm{g}$. Tc/ml. inoculated with a highly resistant culture of Staphylococcus aureus I I I

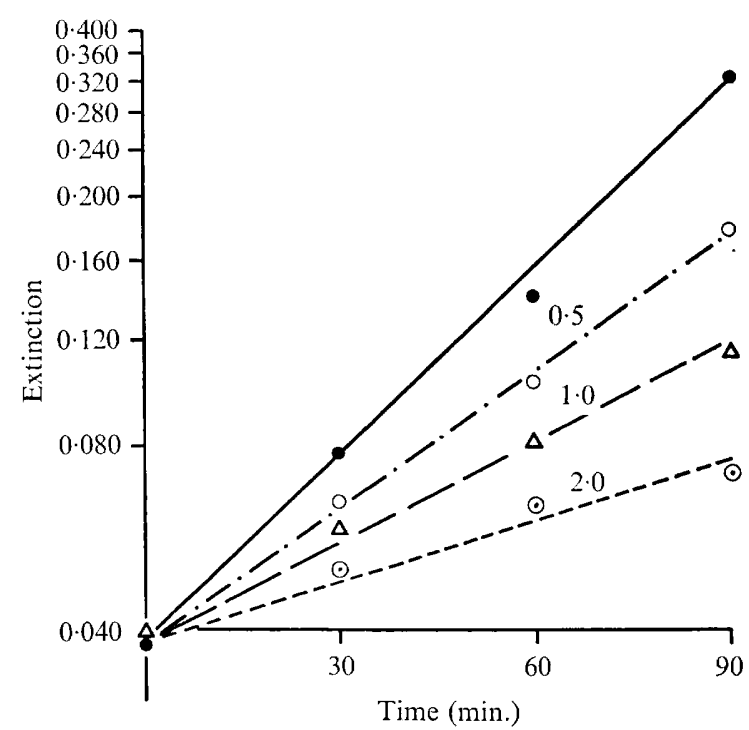

Fig. I. Tetracycline assay using Shigella boydii as test organism. An exponential culture of the test organism was divided into four portions, the indicated concentrations of tetracycline were added to three of the samples, which were incubated at $37^{\circ}$. Extinction of the samples was measured at $660 \mathrm{~nm}$.

aerated at $37^{\circ}$. The control for spontaneous inactivation was uninoculated $\mathrm{NB}+\mathrm{I} 60 \mu \mathrm{g}$. Tc/ml. incubated in the same way. Freshly prepared dilutions of Tc served as references. The experimental samples were cooled immediately in ice, centrifuged at $2^{\circ}$, and the clear supernatant fluid stored at $-20^{\circ}$ until titration. Addition of $0.25 \mathrm{ml}$. of this fluid to $20 \mathrm{ml}$. of an exponential culture of the assay organism (Shigella boydii) would give a final concentration of $2 \cdot 0 \mu \mathrm{g} . / \mathrm{ml}$. if full activity was preserved. The concentration of active Tc was estimated from the generation time compared with cultures inhibited by freshly prepared Tc solutions at $0,0.50$, $\mathrm{I} \cdot \mathrm{O}$ and $2 \cdot 0 \mu \mathrm{g}$. $/ \mathrm{ml}$. (Fig. I). The growth rate was fairly constant during the assay period (90 min.) but not entirely proportional to the drug concentration. In spite of this, more reproducible results were obtained by this method than by diffusion assay (Garrod \& O'Grady, 1968). Ten independent assays of a solution of $0.75 \mu \mathrm{g}$. Tc/ml. gave values between $0.6 \mathrm{I} 5$ and $0.779 \mu \mathrm{g}$. $/ \mathrm{ml}$. (mean $0.7 \mathrm{I} 2 \mu \mathrm{g} . / \mathrm{ml}$., $\sigma= \pm 0.047$ ).

Uptake of tetracycline or $\beta$-apo-5-oxy-tetracycline was examined essentially as indicated by Franklin (1967). Usually, I60 $\mu \mathrm{g}$. Tc/ml. was added to the staphylococcal culture in exponential growth (extinction 0.120 to 0.140 at $660 \mathrm{~nm}$.) and incubation 
at $37^{\circ}$ was continued for $\mathrm{I} h$. Thereafter, samples ( $\mathrm{IO} \mathrm{ml}$.) were cooled, centrifuged, the organisms washed once with $40 \mathrm{ml} .0 \cdot 85 \% \mathrm{NaCl}$ and resedimented. (When cultures of lower turbidity were examined, as in Fig. $5 a$, a correspondingly greater sample volume was used.) The cocci were suspended in $4.0 \mathrm{ml}$. cold perchloric acid $(0.5 \mathrm{M})$, incubated ro min. at room temperature, neutralized with $4.0 \mathrm{ml} \mathrm{NaOH}$ ( $1.0 \mathrm{M}$ ), centrifuged, and the extinction $(380 \mathrm{~nm}$.) of the supernatant determined. Standard solutions of the drug, treated similarly with perchloric acid and $\mathrm{NaOH}$, were used as references. Efficacy of the extraction method was checked by repeating the extraction on the treated bacterial sediment; the tetracycline of the second extract never accounted for more than $5 \%$ of the first extract.

An extinction $(E)$ of 0.240 at $380 \mathrm{~nm}$. in a Zeiss absorption spectrophotometer corresponded to $50 \mu \mathrm{g}$. Tc in the bacterial pellet. By extraction of bacteria not treated with tetracycline, extinction values of -0.03 to +0.02 were obtained (six experiments). No correction for these blank values were made.

Protein content of the bacterial extracts was examined according to Lowry, Rosebrough, Farr \& Randall (I95I); I0 ml. culture of extinction 0. I 20 (660 nm.) contained about $0.23 \mathrm{mg}$. protein. Values of $50 \mu \mathrm{g}$. Tc/mg. bacterial protein were based on direct spectrophotometer readings of 0.06 . Low values of uptake calculated by this method should therefore be accepted with due precaution and interpreted as 'low' or ' $<35 \mu \mathrm{g}$. Tc/mg. protein', but for practical reasons the calculated values are indicated under Results.

Uptake of $\left[{ }^{3} \mathrm{H}\right]$ tetracycline. Some of the uptake experiments, particularly those expected to give low values, were performed with $\left[{ }^{3} \mathrm{H}\right] \mathrm{Tc}$ diluted with nonradioactive Tc. Chloramphenicol (Io $\mu \mathrm{g}$. $/ \mathrm{ml}$.) was used to inhibit growth of the cultures, since uptake of the susceptible and resistant cultures would not be entirely comparable if the resistant culture grew in presence of Tc, whilst the susceptible one did not. Preliminary experiments with sufficient Tc to inhibit growth of the resistant culture showed that Io $\mu \mathrm{g}$. chloramphenicol $/ \mathrm{ml}$. had no influence on Tc accumulation.

In the experiments with $\left[{ }^{3} \mathrm{H}\right] \mathrm{Tc}$, the culture incubated with $\mathrm{Tc}$ contained about $40 \mu \mathrm{g}$. bacterial protein. The radioactivity of Tc (40,000 to 230,000 c.p.m./ml.) was chosen so that the samples with lowest uptake yielded at least 250 c.p.m. After incubation at $37^{\circ}$ for $\mathrm{I} h$. the samples were centrifuged at $2^{\circ}$ and the pellet was washed twice with $2 \mathrm{ml}$. $\mathrm{NB}$ and once with $2 \mathrm{ml}$. distilled $\mathrm{H}_{2} \mathrm{O}$. The supernatant of the last washing contained less than 80 c.p.m. $/ \mathrm{ml}$. To the pellet was added $0.3 \mathrm{ml} .5 \% n$-butanol (Egan \& Morse, 1965) and, after 10 min., the content of the test-tube was transferred to a scintillation vial together with $15 \mathrm{ml}$. of the following scintillation fluid: 16 g. $2 \cdot 5$-diphenyloxazole, $0.8 \mathrm{~g}$. I,4-bis-2(4-methyl-5-phenyloxazolyl)-benzene and $240 \mathrm{~g}$. naphthalene in a mixture of $p$-dioxane $2800 \mathrm{ml}$., methanol $700 \mathrm{ml}$. and ethylene glycol $160 \mathrm{ml}$. The vials were counted in a Packard Tricarb liquid scintillation spectrometer, model 3203, and quenching was determined by external standardization. No correction for radioactivity of the intercellular fluid was attempted.

Uptake of $\left[{ }^{14} \mathrm{C}\right]$ chloramphenicol was examined after incubation in $10 \mu \mathrm{g}$. chloramphenicol $/ \mathrm{ml}$. NB containing 500,000 c.p.m. of $\left[{ }^{14} \mathrm{C}\right]$ chloramphenicol. Cocci were prepared for liquid scintillation as for $\left[{ }^{3} \mathrm{H}\right] \mathrm{Tc}$.

In all examinations of radioactivity, the data quoted are means of three parallel samplings.

Chromatography or Tc (or ${ }^{3} \mathrm{H}-\mathrm{Tc}$ ) was performed by the ascending technique on 
Eastman-Kodak thin-layer silica gel sheets with: butyl acetate + methyl isobutyl ketone $+n$-butanol + water $(5+15+2+22$ by vol.) with 2 vol. formic acid added before use as solvent. Ascending chromatography on Whatman no. I paper was performed with $10 \%$ citric acid as solvent. The paper was cut into strips of $0.5 \mathrm{~cm}$. each which were counted in $10 \mathrm{ml}$. toluene scintillation fluid $(2,5$-diphenyloxazole, $4 \mathrm{~g}$. plus I,4-bis-2(4-methyl-5-phenyloxazolyl)-benzene, $300 \mathrm{mg}$. in I 1. toluene).

Absorption spectrum of tetracycline was examined with a Unicam SP 800 automatic recording spectrophotometer in the range 200 to $450 \mathrm{~nm}$.

\section{RESULTS}

Inactivation of tetracycline (Tc). A high-level resistant strain of Staphylococcus aureus II I was incubated with aeration at $37^{\circ}$ in nutrient broth (NB) and in $160 \mu \mathrm{g}$. Tc/ $\mathrm{ml}$. NB from about $10^{7}$ cocci $/ \mathrm{ml}$. After $24 \mathrm{~h}$., heavy growth was obtained in both cultures (extinction $>0.350$ ). Simultaneously, a susceptible culture was suspended in $\mathrm{NB}$ and in $160 \mu \mathrm{g}$. Tc/ml. NB at an initial extinction of 0.300 and also incubated. After $24 \mathrm{~h}$. all four cultures were sedimented by centrifugation, and the clear supernatant fluid separated from the bacterial pellet.

This supernatant was diluted in $0 . \mathrm{IIN}-\mathrm{HCl}(\mathrm{I}: 8)$, and the absorption spectrum recorded, using the diluted supernatants of the corresponding drug-free cultures as blanks. The absorption spectrum was compared with that of freshly prepared $\mathrm{I} 60 \mu \mathrm{g}$. Tc/ml. NB also diluted $\mathrm{I}: 8$ in $0 . \mathrm{I} \mathrm{I} \mathrm{N}-\mathrm{HCl}$. Figures $2 a, b$ show that incubation with susceptible or resistant staphylococci had no influence on the absorption maxima at 356,273 and 220 to $225 \mathrm{~nm}$. due to drug. The exact positions and relative heights of the absorption peaks varied when different nutrient media were used (NB, Bacto penassay, Bacto tryptose phosphate broth) and even with different batches of the same medium. This was especially marked in the short wave u.v. because of the high absorption of the nutrient broth blank in the 200 to $230 \mathrm{~nm}$. region. The absorption spectrum of $\mathrm{Tc}$ in $0 . \mathrm{I} \mathrm{N}-\mathrm{HCl}$ demonstrated a well-defined peak at $220 \mathrm{~nm}$. This peak was not so apparent in a nutrient broth solution probably as a result of interference by the broth (Fig. $2 a, b$ ).

Five $\mathrm{ml}$. of the supernatant samples were lyophilized, redissolved in $0.25 \mathrm{ml} . \mathrm{H}_{2} \mathrm{O}$ and chromatographed with paper and thin-layer silica gel techniques. The Tc spots on silica gel were easily recognized by their golden fluorescence (u.v. short-wave lamp); after a few days the spots oxidized in the air and turned dirty golden. On paper, the Tc spots were visualized after spray with $\mathrm{HCl} / \mathrm{N}$ and heating to $50^{\circ}$ for $30 \mathrm{~min}$. Comparable $R_{F}$ values were obtained repeatedly on all samples, on thin layer 0.48 to $0.5 \mathrm{I}$ and on paper 0.70 to 0.75 . Anhydrotetracycline prepared by acid treatment of Tc (Kelly, Peets \& Hoyt, I969) had $R_{F}$ of 0.18 on thin layer and 0.23 on paper.

The sedimented cocci from the same cultures were extracted with perchloric acid and the extract neutralized with $\mathrm{NaOH}$, as described under Methods, before examination for uptake of Tc. The extract of the susceptible culture incubated with Tc had the same absorption spectrum as solutions of Tc. In this case, the blank was an extract of bacteria grown in drug-free NB. A lyophilized sample of the former extract (susceptible cocci incubated in $\mathrm{NB}+\mathrm{Tc}$ ) when examined chromatographically showed a spot with the same $R_{F}$ values as pure Tc. Resistant cocci treated in the same manner showed no characteristic absorption, possibly due to the inadequate amount 
of the drug present in this extract. The Tc of this extract could not be visualized by chromatography on paper with citric acid as solvent.

If the resistant staphylococci overcome the inhibiting effect of Tc by inactivating it intracellularly, this might be demonstrated more easily when the drug concentration is moderate than with high concentrations, since a greater fraction of the drug should be metabolized.
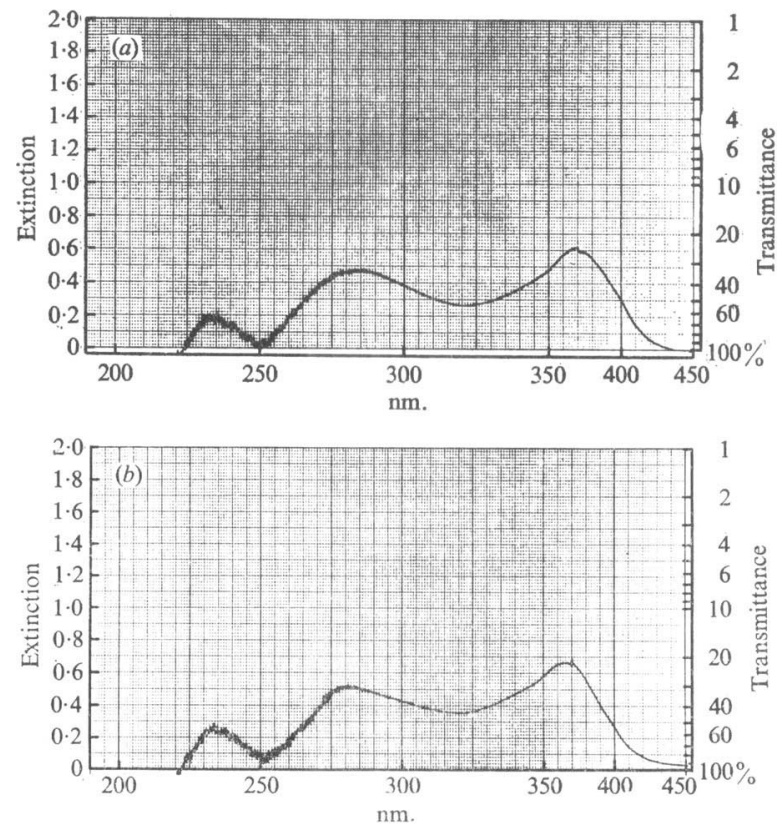

Fig. 2. Absorption spectrum of tetracycline in the range 200 to $450 \mathrm{~nm}$. (a) Tetracycline (Tc) $160 \mu \mathrm{g} . / \mathrm{ml}$. in nutrient broth (NB) diluted $\mathrm{I}: 8$ with $\mathrm{H}_{2} \mathrm{O}$. Blank: drug-free NB diluted I : 8 with $\mathrm{H}_{2} \mathrm{O}$. (b) A highly resistant strain of Staphylococcus aureus I I I was grown in NB+ $160 \mu \mathrm{g}$. Tc/ml. and in drug-free nutrient broth. After $24 \mathrm{~h}$. the cultures were centrifuged, and the supernates diluted in $\mathrm{H}_{2} \mathrm{O}_{\mathrm{I}}: 8$. The absorption spectrum of the tetracycline sample was examined with the drug-free sample in the blank cuvette.

A similar study was therefore undertaken with the high-level resistant strain incubated during $24 \mathrm{~h} .\left(37^{\circ}\right)$ in $20 \mu \mathrm{g}$. Tc/ml. NB containing [ $\left.{ }^{3} \mathrm{H}\right] \mathrm{Tc}(500,000 \mathrm{c} . \mathrm{p} . \mathrm{m} . / \mathrm{ml}$. After $24 \mathrm{~h}$. lyophilized samples of the supernatant fluid and control solutions of Tc were chromatographed on paper, which was cut into $0.5 \mathrm{~cm}$. pieces and the radioactivity determined by liquid scintillation. The radiograms showed a peak at $R_{F} 0 \cdot 72$ (Fig. 3). A radiogram from the cocci extracted with $4 \mathrm{ml}$. perchloric acid, lyophilized and again dissolved in $0 . \mathrm{I} \mathrm{ml} . \mathrm{H}_{2} \mathrm{O}$ also yielded a peak at $R_{F} 0.72$.

The biological activity of $\mathrm{Tc}$ in a resistant culture in $\mathrm{I} 60 \mu \mathrm{g}$. Tc/ml. NB was assayed periodically during I I days; the amounts demonstrated were comparable to those found in NB + Tc incubated in the same way (Fig. 4).

No evidence was thus obtained indicating inactivation or metabolism of Tc during growth of a resistant culture of Staphylococcus aureus I I in NB + Tc.

Accumulation of tetracycline. Figure $5 a$ depicts variations in the ability to accumulate Tc intracellularly of organisms from three cultures of Staphylococcus aureus I I : (i) a susceptible (eliminated) strain grown in NB; (ii) a highly resistant strain grown in 
$\mathrm{NB}$; and (iii) this latter strain grown in $4.0 \mu \mathrm{g}$. Tc/ml. NB. The high-level resistant strain was maintained by daily transfer on $160 \mu \mathrm{g}$. Tc/ml. NA. Uptake was examined after addition of $160 \mu \mathrm{g}$. Tc/ml. to samples of the cultures and incubation at $37^{\circ}$

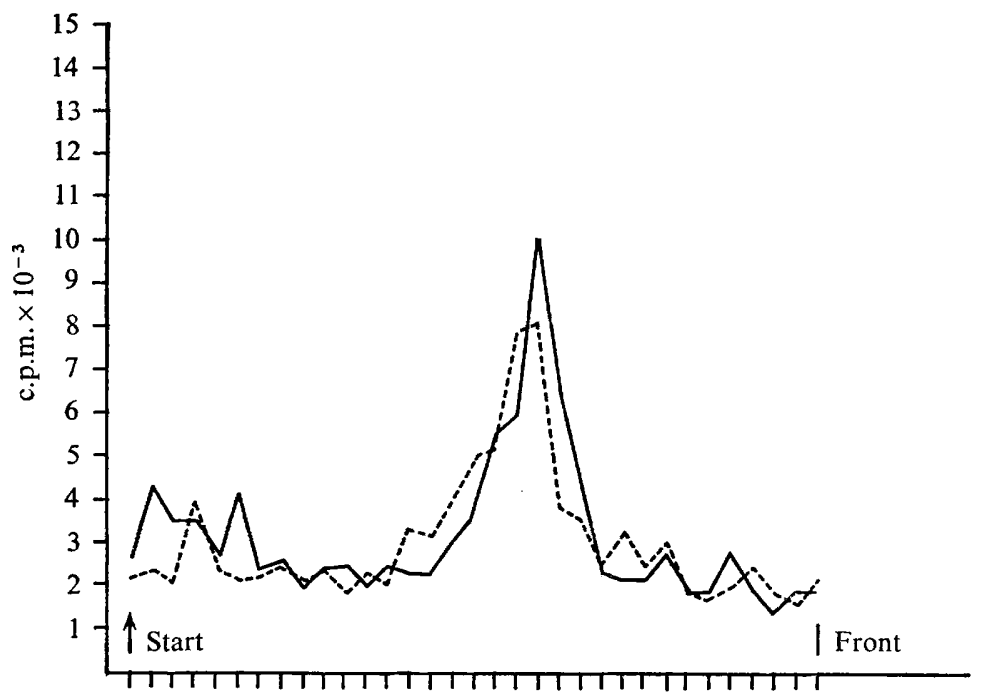

Fig. 3. Radiograms of $\left[{ }^{3} \mathrm{H}\right]$ tetracycline. A $24 \mathrm{~h}$. culture of a high-level resistant strain of Staphylococcus aureus I I in NB $+20 \mu \mathrm{g}$. Tc/ml. (500,000 c.p.m. of $\left.{ }^{3} \mathrm{H}\right)$ was cleared by centrifugation and the supernatant chromatographed on paper. The paper was cut in strips of $0.5 \mathrm{~cm}$. width and counted by liquid scintillation. The radiogram (-) was constructed from the c.p.m. of each strip. For the sake of comparison, uninoculated tritiated tetracycline in nutrient broth was treated similarly and chromatographed $(\ldots \ldots \ldots)$.

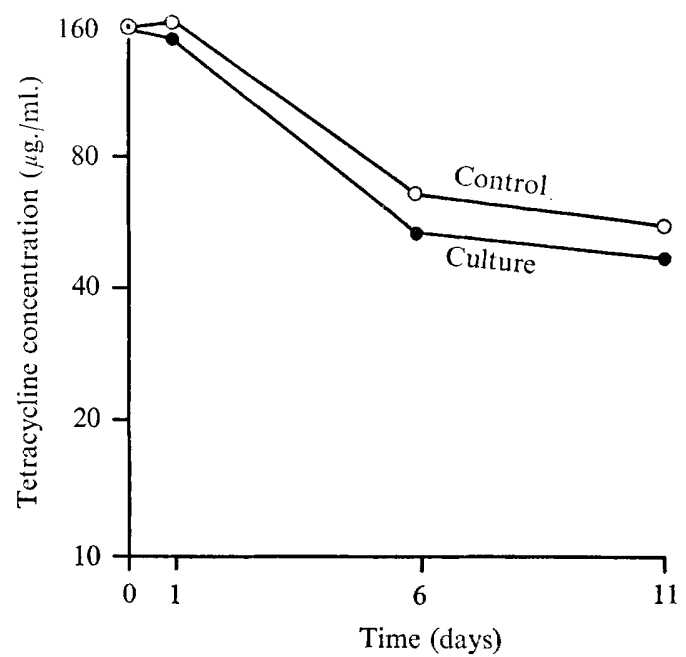

Fig. 4. Stability of tetracycline during growth of Staphylococcus aureus I I I (a high-level resistant culture) at $37^{\circ}$ in nutrient broth with $160 \mu \mathrm{g}$. Tc/ml. (- Inoculum $10^{7} \mathrm{cocci} / \mathrm{ml}$; extinction at $660 \mathrm{~nm}$., at $24 \mathrm{~h}$. 0.400 . At the indicated times, residual Tc was assayed biologically (see Methods). As a control for spontaneous decomposition of the drug, uninoculated nutrient broth with $\mathrm{I} 60 \mu \mathrm{g}$. Tc/ml. was incubated and examined simultaneously $(\mathrm{O}-\mathrm{O}-\mathrm{O})$. 
during $\mathrm{I}$ h. In the susceptible strain, concentrating ability of the cocci reached a maximum towards the end of the exponential growth phase, and decreased thereafter rapidly. Maximal accumulation was $338 \mu \mathrm{g}$. Tc/mg. bacterial protein (a more than Ioo-fold concentration). The resistant strain grown in $4.0 \mu \mathrm{g}$. Tc/ml. NB concentrated the drug to a low degree at all stages of growth. When this strain was grown in NB alone, accumulating ability was minimal during the first half hour, but thereafter it gradually approached that of the susceptible culture.

From these results it is evident that a resistant culture either accumulates Tc to a far lesser degree than a susceptible one, or else that the drug is altered after accumulation in a resistant culture so that it no longer absorbs at $380 \mathrm{~nm}$. Accumulation was therefore measured using tritiated Tc. In this study, 10 $\mu \mathrm{g}$. chloramphenicol $/ \mathrm{ml}$. was added to all the samples during incubation with $\mathrm{I} 60 \mu \mathrm{g}$. Tc/ml. in order to ensure that no growth occurred in the resistant cultures; the experimental conditions for the susceptible and resistant culture were therefore more strictly comparable. The results shown in Fig. $5 b$ are similar to those of Fig. $5 a$. The accumulation of $\left[{ }^{14} \mathrm{C}\right]$ chloramphenicol by the susceptible (eliminated) strain also varied with the growth phase (Fig. $5 b$ ). Uptake of chloramphenicol has been shown to depend on both the energetic state of the bacteria (Vazquez, 1963) and the number of ribosomes (Hurwitz \& Braun, I967). Uptake of $\left[{ }^{14} \mathrm{C}\right]$ chloramphenicol by the resistant Staphylococcus aureus I I growing in $4^{\circ} \mathrm{o} \mu \mathrm{g}$. Tc/ml. NB was measured only at $90 \mathrm{~min}$. and was virtually identical to that of the susceptible strain at that time, showing that decreased uptake of Tc was not a non-specific effect of that drug.

\section{Table I. Uptake of $\left[{ }^{3} \mathrm{H}\right]$ tetracycline by Staphylococcus aureus III}

$S$. aureus II I was grown in nutrient broth to the exponential growth phase $(E=0.160)$ and then diluted $1: 5$ in nutrient broth containing the indicated drugs. After 1 h. at $37^{\circ}$ (aeration), $20 \mu \mathrm{g} . / \mathrm{ml}$. tetracycline containing 175,000 c.p.m. $\left[{ }^{3} \mathrm{H}\right]$ tetracycline was added. Uptake was measured by liquid scintillation as described under Methods.

\begin{tabular}{|c|c|}
\hline Pre-incubation condition ( $\mathrm{I}$ h.) & $\begin{array}{l}\text { Accumulation of } \\
\text { tetracycline } \\
\text { in } \mu \mathrm{g} / \mathrm{mg} \text {. } \\
\text { bacterial protein }\end{array}$ \\
\hline Nalidixic acid $200 \mu \mathrm{g} . / \mathrm{ml}$. & $54 \cdot 8$ \\
\hline $\begin{array}{l}\text { Nalidixic acid } 200 \mu \mathrm{g} / / \mathrm{ml} \text {. } \\
+ \text { tetracycline } \mathrm{I} \cdot 0 \mu \mathrm{g} . / \mathrm{ml} \text {. }\end{array}$ & $31 \cdot 7$ \\
\hline $\begin{array}{l}\text { Nalidixic acid } 200 \mu \mathrm{g} . / \mathrm{mI} \text {. } \\
+ \text { tetracycline } \sigma^{\cdot} \mathrm{I} \mu \mathrm{g} . / \mathrm{mI} \text {. }\end{array}$ & $26 \cdot 4$ \\
\hline $\begin{array}{l}\text { Nalidixic acid } 200 \mu \mathrm{g} . / \mathrm{ml} \text {. } \\
\text { + actinomycin D } \mathrm{I} \cdot 5 \mu \mathrm{g} . / \mathrm{ml} \text {. } \\
\text { + tetracycline } \mathrm{r} \cdot 0 \mu \mathrm{g} . / \mathrm{ml}\end{array}$ & $5 \mathrm{I} \cdot 8$ \\
\hline
\end{tabular}

Figures $5 a, b$ show that a decreased accumulating ability of the high-level resistant strain was maintained by subculturing with $4^{\circ} 0 \mu \mathrm{g}$. Tc/ml. In a Tc-susceptible (eliminated) culture of Staphylococcus aureus I I I, growth in $0.05 \mu \mathrm{g}$. Tc/ml. NB had no effect on subsequent uptake of $\left[{ }^{3} \mathrm{H}\right] \mathrm{Tc}$ when compared with uptake by organisms grown in plain NB. It was therefore assumed that a lowered uptake depends on the presence of a gene on the resistance plasmid and that the synthesis of 'resistance protein' is generally repressed but may be derepressed by the drug (Sompolinsky et al. 1970). If repression in this system is effected on the level of transcription, addition of actino- 
mycin D should inhibit the synthesis of the resistance protein. Table I shows that induction occurred in the presence of an inhibitor of DNA replication (nalidixic acid), but not when DNA-dependent RNA synthesis was inhibited by actinomycin D. The study reported in this table was performed with an entirely uninduced resistant culture that was maintained by frequent transfers on plain NA. In this strain, preincubation with $0 \cdot \mathrm{I} \mu \mathrm{g}$. Tc/ml. was sufficient to reduce accumulation of the drug by $50 \%$ after challenge with $20 \mu \mathrm{g}$. Tc/ml.
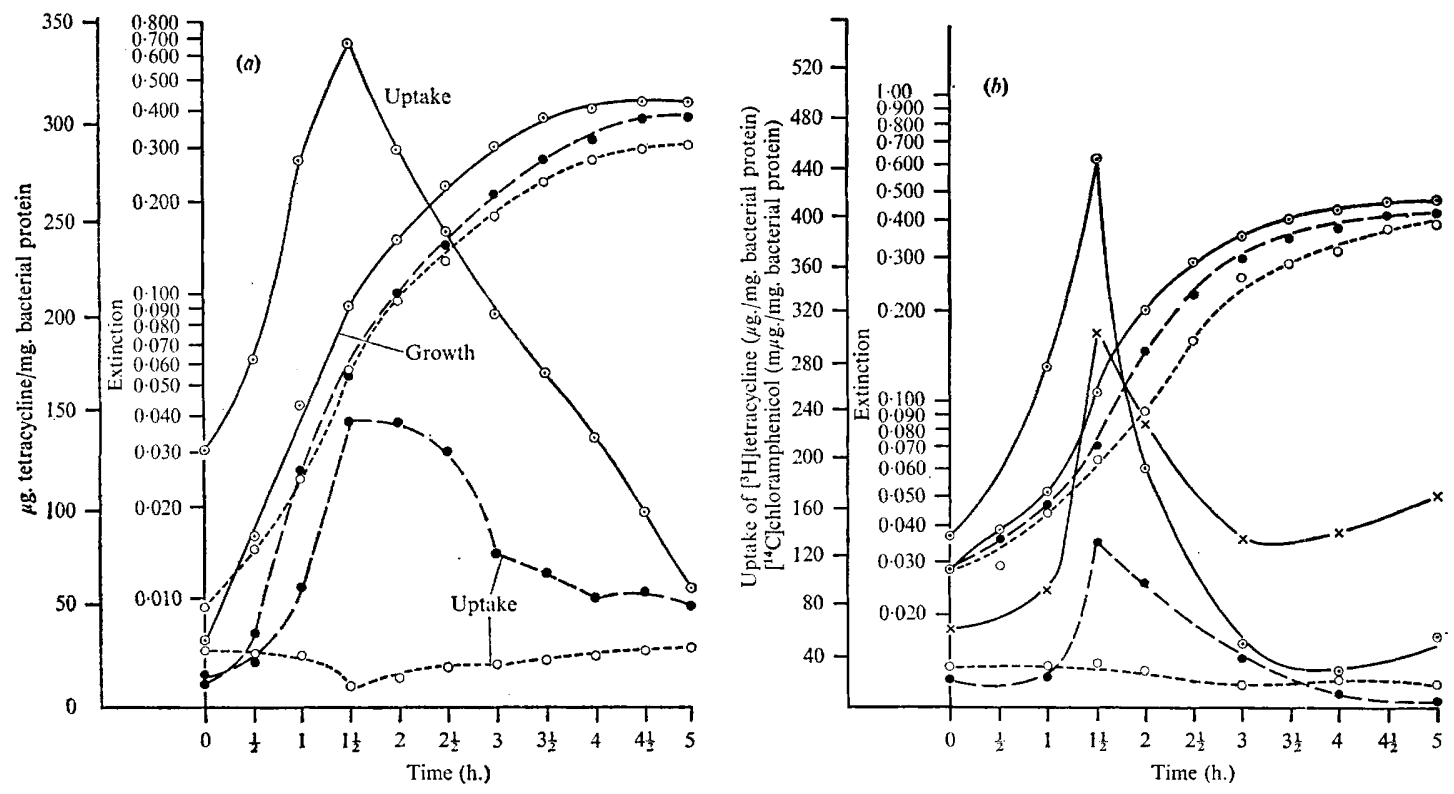

Fig. $5 a$. Uptake of tetracycline by Staphylococcus aureus I I I during different growth phases. $\odot-\odot$, Growth and uptake by a susceptible (eliminated) strain after growth in nutrient broth; - indicates a high-level resistant strain after growth in nutrient broth, and $O \ldots . . . O$ after growth in $4.0 \mu \mathrm{g}$. Tc/ml. NB. Uptake was determined as $E_{380} \mathrm{~nm}$. of bacterial extracts after incubation with $\mathrm{I} 60 \mu \mathrm{g}$. $/ \mathrm{ml}$. tetracycline (see Methods).

Fig. $5 b$. Uptake of tetracycline by Staphylococcus aureus I I d during different growth phases measured as radioactivity after incubation with $160 \mu \mathrm{g}$. Tc/ml. containing tritiated Tc I 50,000 c.p.m./ml.). Legends as for Fig. 5a. Uptake of chloramphenicol $(x-x-x)$ examined in the susceptible strain, after incubation with chloramphenicol $10 \mu \mathrm{g} . / \mathrm{ml}$. containing 500,000 c.p.m./ml. $\left[{ }^{14} \mathrm{C}\right]$ chloramphenicol.

\section{Table 2. Uptake of tetracycline by Staphylococcus aureus III under various conditions}

Sodium azide (o.or M) was added to the samples simultaneously with the tetracycline.

$\mu \mathrm{g}$. Tetracycline/mg. bacterial protein

$\begin{array}{lccc}\text { Incubation } & \begin{array}{c}\text { Susceptible strain } \\ \text { in NB }\end{array} & \begin{array}{c}\text { Resistant strain } \\ \text { in NB }\end{array} & \begin{array}{c}\text { Resistant strain } \\ \text { in } 4.0 \mu \mathrm{g} \text {. Tc/ml. NB }\end{array} \\ 37^{\circ} & 320 & 158 & \text { I I } \\ 0^{\circ} & 25 & 7 & \mathrm{nt} \\ 37^{\circ} \text {, with } & 38 & 15 & 7 \\ 10^{-2} \mathrm{M} \text {-sodium } & & & \\ \text { azide } & & & \end{array}$

Abbreviations: $\mathrm{NB}=$ nutrient broth $; \mathrm{Tc}=$ tetracycline; $\mathrm{nt}=$ not examined. 
Table 2 shows that uptake was much less at $0^{\circ}$ and the presence of sodium azide (O.OIM). Similar results were obtained when uptake was examined using $\left[{ }^{3} \mathrm{H}\right] \mathrm{Tc}$ ( $160 \mu \mathrm{g}$. Tc $/ \mathrm{ml}$. + Io $\mu \mathrm{g}$. chloramphenicol $/ \mathrm{ml}$.).

The connexion between uptake and resistance became particularly evident when uptake was studied as a function of external drug concentration (Fig. 6). For the susceptible strain in the exponential growth phase, the uptake was more or less proportional to the drug concentration in the medium, in the range 40 to $320 \mu \mathrm{g} . / \mathrm{ml}$., and had then reached a maximum of $468 \mu \mathrm{g} . / \mathrm{mg}$. protein. In the highly resistant strain,

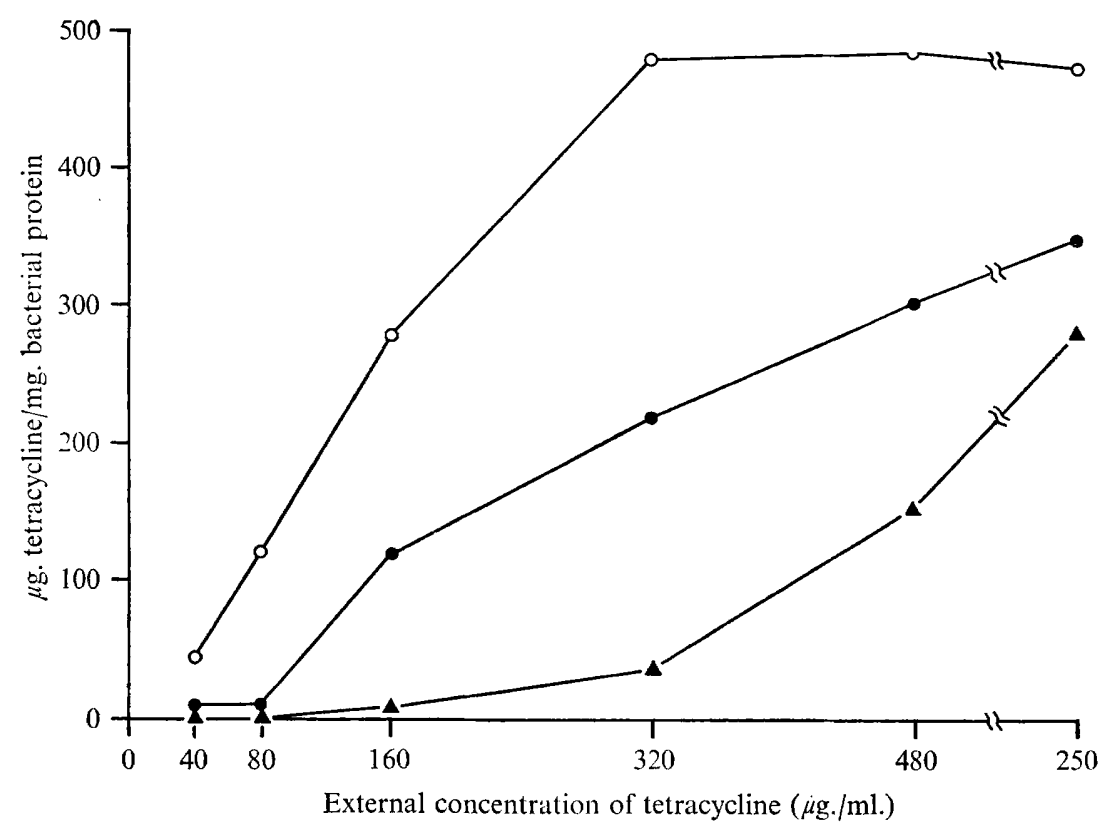

Fig. 6. Uptake of tetracycline by Staphylococcus aureus II I at differunt external concentrations of the drug. $\mathrm{O}-\mathrm{O}, \mathrm{A}$ susceptible (eliminated) culture grown in nutrient broth; - - a high-level resistant culture grown in nutrient broth; $\mathbf{\Delta}-\mathbf{\Delta}$, a high-level resistant culture grown in nutrient broth $+4.0 \mu \mathrm{g}$. Tc/ml. The drug was added to samples of exponential growing cultures $\left(37^{\circ}\right)$.

derepressed through growth in plain NB during $2 \mathrm{~h}$., subsequent uptake was not affected by increase in external Tc concentration from 40 to $80 \mu \mathrm{g} . / \mathrm{ml}$. but increased strongly when the drug concentration was further increased. When the resistant organism was grown in $4.0 \mu \mathrm{g}$. Tc/ml NB, subsequent uptake was little influenced by variations in external Tc concentrations of $\mathrm{I} 60$ to $320 \mu \mathrm{g} . / \mathrm{ml}$., but thereafter the slope in the uptake curve increased steeply. We did not succeed in the examination of uptake at higher concentrations, since the cultures underwent gross lysis. We therefore do not know if maximal uptake is identical in resistant and susceptible cultures. Uptakes by a non-induced resistant and by a susceptible strain at low external drug concentration were compared through the use of tritiated Tc (Fig. 7). The uptake by the resistant strain was influenced by the external concentration only when the Tc concentration exceeded $5 \mu \mathrm{g} . / \mathrm{ml}$.

From these results, it seems justifiable to assume that the highest concentration of Tc 


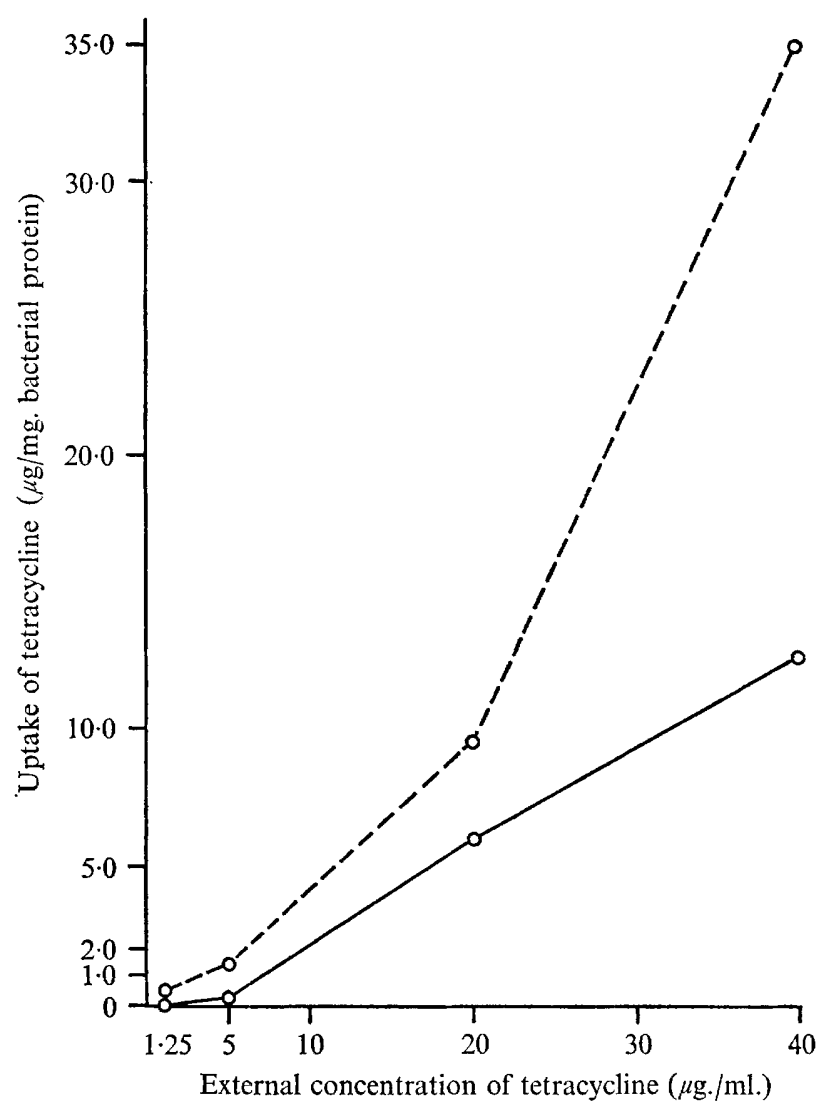

Fig. 7. Uptake of $\left[{ }^{3} \mathrm{H}\right]$ tetracycline by a susceptible (eliminated) and a low-level resistant (non-induced) culture of Staphylococcus aureus Ir I as a function of outer drug concentration. Legends as for Fig. 6, but uptake calculated by radioactivity of the cocci measured by liquid scintillation.

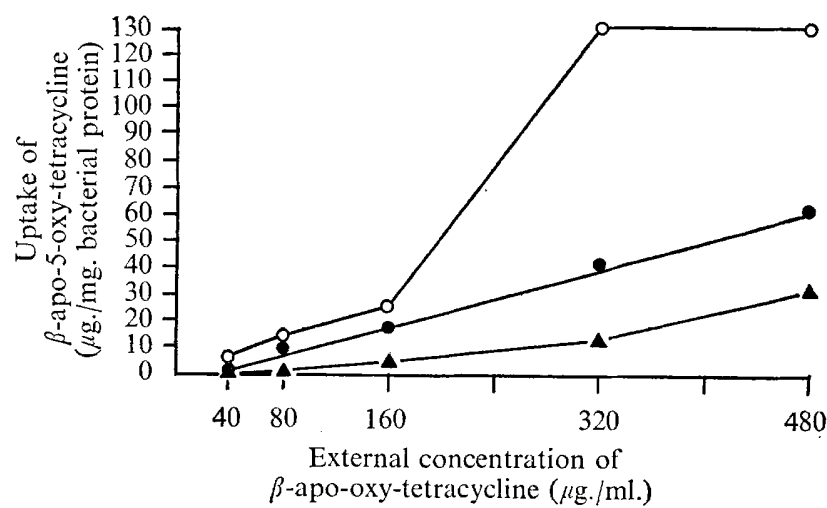

Fig. 8. Uptake of $\beta$-apo-5-oxy-tetracycline by Staphylococcus aureus. Legends as for Fig. 2. 
which does not cause an increase in uptake by non-induced organisms reflects the level of their resistance. Similar observations were recently reported for Escherichia coli (DeZeeuw, 1968). It should also be mentioned that $\beta$-apo-5-oxy-tetracycline, which is only very slightly inhibitory, was accumulated to a relatively slight degree, even by the susceptible culture (Fig. 8).

\section{DISCUSSION}

Development of bacterial resistance to a chemotherapeutic drug which is associated with an extrachromosomal genetic unit is most likely, albeit not necessarily, due to the occurrence of an entirely new cell product not present in the susceptible strain. An inactivating enzyme would be an attractive candidate for such a product, and indeed inactivation of penicillin (Datta \& Kontomichalou, I965), chloramphenicol (Shaw, I967) and aminoglycoside antibiotics (Okamoto \& Suzuki, 1965) has been described in bacteria that owe their resistance to extrachromosomal DNA.

If inactivation were the way in which Staphylococcus aureus II I overcomes the inhibiting action of tetracycline, the drug could either be entirely inactivated so that the concentration in the growth medium decreases below the tolerated level of the susceptible culture lacking a resistance plasmid, or it could be altered intracellularly so that the affinity to the site of action decreases but the altered molecules still remain bound to the permease system, thereby preventing further entrance of active drug from the surrounding medium.

In our case, no evidence for inactivation was borne out experimentally, since the drug in the nutrient medium after full growth of a resistant strain remained unaltered both in its spectrophotometric and chromatographic characteristics, and also biological activity could be demonstrated in the range comparable with an uninoculated control sample. In addition, the tetracycline extracted from resistant organisms after growth in Tc-containing medium was recognizable by its characteristic $R_{F}$ on paper chromatography. Furthermore, we have demonstrated a decreased uptake of the drug by the resistant strain. If this was due partly to alteration of the drug intracellularly, with alteration of extinction at $380 \mathrm{~nm}$. and with excretion to the surrounding medium of the $\left[{ }^{3} \mathrm{H}\right]$-containing fragment from the tetracycline $-7-{ }^{3} \mathrm{H}(\mathrm{N})$, then extensive alteration of the molecule would have occurred, and Tc molecules from the medium would probably rapidly replace those metabolized. No new radioactive product was found by chromatography of the $\left[{ }^{3} \mathrm{H}\right]$-Tc containing medium after growth of the resistant strain.

We conclude, therefore, that resistance to Tc in Staphylococcus aureus I I results from a decreased accumulation of the drug, as was demonstrated for Tc resistance in Escherichia coli (Izaki, Kiuchi \& Arima, 1966; Franklin, 1967; DeZeeuw, 1968).

Decreased uptake due to a resistance plasmid might be due to (i) a gene product functioning as a repressor on the chromosomal operon coding for the active uptake system; (ii) a product combining with and inactivating the uptake system; or (iii) a product which facilitates transport of Tc molecules out of the cell, thereby competing with the uptake system. Further studies will be necessary to decide between these possibilities.

Decreased uptake of the Tc proved inducible, as was the case with phenotypical resistance (Sompolinsky et al. 1970), and in both cases the drug served as inducer. Since it has recently been suggested that induction of penicillinase synthesis occurs at the translation level (Csanyi, Jacobi \& Straub, 1967), we felt it important to verify in 
an uptake experiment our previous claim that induction is inhibited by actinomycin D (Sompolinsky et al. 1970), thereby proving that at least for Tc resistance in Staphylococcus aureus II I induction occurs on the level of transcription.

The authors are grateful to Mrs Aviva Belz and Miss Hernia deVries for skilful help during the performance of this study. Lederle Research Laboratories generously provided the tritiated tetracycline used. Our thanks are also due to Dr Meir Perl and Professor A. Pinsky of the Department of Biochemistry, Bar Ilan University, as well as Mr David Teram from Asaf Harofe Government Hospital, who assisted in preparation of the manuscript. A part of this study was supported by research grant 64/3/32 from Bar Ilan University.

\section{REFERENCES}

Csanyi, V., JAcobi, G. \& StraUb, B. F. (1967). The regulation of penicillinase synthesis. Biochimica et Biophysica Acta I45, 470-484.

Datta, N. \& Kontomichalou, P. (1965). Penicillinase synthesis controlled by infectious R factors in Enterobacteriaceae. Nature, London 208, 239-241.

DeZeEUw, J. R. (I968). Accumulation of tetracyclines by Escherichia coli. Journal of Bacteriology 95 , 498-506.

EgAN, J. B. \& MoRse, M. L. (1965). Carbohydrate transport in Staphylococcus aureus. II. Characterization of the defect of a pleiotropic transport mutant. Biochimica et Biophysica Acta 109, 172-183.

FrankLIN, T. J. (1967). Resistance of Escherichia coli to tetracyclines. Changes in permeability to tetracyclines in Escherichia coli bearing transferable resistance factors. Biochemical Journal ro5, $37 \mathbf{I}-\mathbf{3 7 8 .}$

Garrod, L. P. \& O'Grady, F. (1968). Antibiotic and Chemotherapy and edition. Edinburgh: E. and S. Livingstone.

Hurwitz, C. \& Braun, C. B. (1967). Measurement of binding of chloramphenicol by intact cells. Journal of Bacteriology 93, I671-1676.

IZAKI, K., KIUCHI, K. \& ARIMA, K. (1966). Specificity and mechanism of tetracycline resistance in a multiple drug resistant strain of Escherichia coli. Journal of Bacteriology 91, 628-663.

Kelly, R. G., PeETS, L. M. \& Hoyt, K. D. (1969). A fluorometric method of analysis for tetracycline. Analytical Biochemistry 22, 222-229.

Lowry, O. H., Rosebrough, N. J., FARR, A. L. \& Randall, R. J. (I95I). Protein measurement with the Folin phenol reagent. Journal of Biological Chemistry 193, $265-275$.

Окамото, S. \& SUZUKI, Y. (1965). Chloramphenicol-, dihydrostreptomycin- and kanamycininactivating enzymes from multiple drug-resistant Escherichia coli carrying episome R. Nature, London 208, 1301-1303.

SHAw, W. V. (1967). The enzymatic acetylation of chloramphenicol by extracts of $\mathrm{R}$ factor resistant Escherichia coli. Journal of Biological Chemistry 242, 687-693.

Sompolinsky, D., Krawitz, T., ZaidenZaiG, Y. \& AbRamova, N. (I970). Inducible resistance to tetracycline in Staphylococcus aureus. Journal of General Microbiology 62, 34I-349.

SompolinsKy, D. \& SAMRA, Z. (I968). Mechanism of high-level resistance to chloramphenicol in different Escherichia coli variants. Journal of General Microbiology 5o, 55-66.

VAZQueZ, D. (1963). Antibiotics which affects protein synthesis: The uptake of $\left[{ }^{14} \mathrm{C}\right]$ chloramphenicol by bacteria. Biochemical and Biophysical Research Communication 12, 409-473. 